\title{
Genetic Modifiers and Subtypes in Schizophrenia
}

\author{
Sarah E. Bergen
}

Published online: 2 October 2014

(C) Springer International Publishing AG 2014

\begin{abstract}
The vast differences observed in clinical features of schizophrenia are undoubtedly mediated in part by genetic influences. Schizophrenia has been conceptualized as either a collection of disorders with overlapping features or a singular diagnostic entity with modifying influences giving rise to the observed range of manifestations. Accordingly, attempts to connect genetic and phenotypic heterogeneity have predominantly investigated the genetic foundations for clinically defined subgroups or explored the effects of putative risk genes on observed variation in schizophrenia. Some evidence exists to support both perspectives, and they are not mutually exclusive. The past few years have witnessed revolutionary advances in the understanding of the genetic risk factors for schizophrenia. Subsequent investigations of genetic and clinical heterogeneity have begun to integrate these findings and make use of the genotyping advances, allowing genome-wide and rare variation to be studied more readily. Recent studies incorporating symptoms, family history, age at onset, severity, sex, cognition, and environmental influences as either subtypes with a genetic basis or features modified by genetic loci are reviewed herein.
\end{abstract}

Keywords Genetic heterogeneity · Age of onset . Pharmacogenomics · Gene-environment interaction . Schizophrenia $\cdot$ Modifier genes

S. E. Bergen $(\bowtie)$

Department of Medical Epidemiology and Biostatistics, Karolinska Institutet, Box 281, 17177 Stockholm, Sweden

e-mail: sbergen@gmail.com

S. E. Bergen

Stanley Center for Psychiatric Research, Broad Institute of MIT and Harvard, Cambridge, MA, USA

\section{Introduction}

It is hard to overstate the range of possible manifestations schizophrenia can exhibit. The clinical features of schizophrenia can include social withdrawal, flattened affect, delusions, hallucinations, disorganized thoughts and speech, cognitive dysfunction, and many other symptoms, although the pattern and severity of symptoms vary widely. In combination with potential ages of onset ranging from childhood to old age, and outcomes spanning chronic unremitting psychosis to full recovery, the expression of schizophrenia is unlikely to be similar between any two patients with this diagnosis.

This considerable clinical heterogeneity has invited numerous attempts to understand its foundations, and two main paradigms have been employed to try to understand the basis for this variation. The first of these conceptualizes schizophrenia as an umbrella term encompassing multiple subtypes with distinct or partially overlapping etiologies and somewhat convergent phenotypes (attributed to Bleuler [1]). Alternatively, schizophrenia has been treated as a singular diagnostic entity with modifying influences giving rise to divergent expression of clinical features (in line with a Kraeplinian perspective [2]). As with many competing scientific perspectives (e.g. nature vs. nurture), the truth is likely to emerge as a blend of both.

The relationship between modifier loci and subtypespecific risk genes is not always clear. For example, a search for modifiers could instead identify susceptibility genes in a subgroup enriched for the clinical phenotype of interest [3]. Furthermore, whether a given phenotype is examined for modifier or potential subtyping properties can depend on its treatment as a quantitative trait or binary variable. For example, age of onset is a continuous measure often operationalized as early versus late onset.

While it is implicit that genetic subtypes of schizophrenia involve genetic risk loci, genetic modifiers may or may not also confer risk for a disorder. Many studies have focused on 
modifier properties of putative genetic risk loci to elucidate their behavioral ramifications and because they represent a more tractable starting point than the full genome. Although it is quite likely that some genetic risk loci also modify the presentation of this disorder, modifier loci could act independently of disease risk [4]. For example, pubertal onset has been associated with timing of onset for schizophrenia in women [5]. Therefore, genetic influences on pubertal timing ostensibly correlate with schizophrenia onset, but these loci would not confer risk for schizophrenia per se. Consequently, genomic scans for modifier loci are also necessary.

In practice, genetic studies of heterogeneity in schizophrenia have been carried out from either a genetic perspective (i.e. association studies between carriers of putative genetic risk variants and clinical variation) or a clinical one (i.e. testing phenotypically defined groups of patients for association with genetic markers).

An excellent overview of the research on this topic was compiled by Fanous and Kendler in 2008 [6]. Since this time, most domains of phenotypic variation incorporated into research studies have remained relatively consistent, including symptoms, age of onset, sex, cognition, illness severity, and family history. Our assessment of genetic variation, on the other hand, has undergone dramatic evolution, and the intervening years have witnessed a gradual shift from linkage and candidate gene studies to genome-wide association studies (GWAS) and GWAS-derived risk genes. Rare genetic variation such as copy number variants (CNVs) and single basepair changes detected through sequencing are also gaining in popularity. This review aims to provide an update on the current state of knowledge regarding genetic modifiers and subtypes in schizophrenia.

\section{Symptoms}

The extreme differences in symptom profiles exhibited by people with schizophrenia have engendered a great deal of interest in the genetic underpinnings for this observation. Numerous inventories exist to assess positive and negative symptoms and occasionally others such as depressive or disorganized symptoms of schizophrenia. Items within each symptom domain are often summed to create composite scores, or clustering techniques such as factor analysis can be applied to reduce the number of statistical tests.

Schizophrenia candidate genes within dopamine pathways have been popularly studied in relation to symptoms. For example, several small $(\mathrm{N}<300)$ association studies of COMT, involved in dopamine catabolism, have been conducted yielding significant associations with negative symptom levels in some studies [7-9], but no symptom associations in others $[10,11]$. The $D B H$ gene, encoding an enzyme in the dopamine biosynthetic pathway, was significantly associated with positive symptoms in a sample of 747 cases [12], and, in a separate study, $D R D 2$, a dopamine receptor, was associated with negative symptoms in 2,408 cases [13].

Additional candidate genes with mixed evidence for involvement in the etiology of schizophrenia have also been investigated as possible modifiers of symptoms within this disorder. The $B D N F \mathrm{val} /$ met polymorphism was implicated in modulation of anxiety/depression symptoms in one study $(\mathrm{N}=456)$ [14] and negative symptoms in another $(\mathrm{N}=375)$ [15]. Variation in the manganese superoxide dismutase gene, $m n S O D$, was also associated with negative symptoms in one study involving 522 patients [16] but not another with only 216 subjects [17]. The gamma-aminobutyric acid (GABA) transporter SLC6A12 was implicated in negative symptom modulation in 283 Korean schizophrenia patients [18]. NRG1 markers have been associated with positive symptoms in a large German sample $(\mathrm{N}=1,071)$ [19], and a short tandem repeat in RELN was associated with both positive and negative symptoms in a Finnish family sample comprising 983 affected and unaffected individuals [20]. A study relating symptoms to single nucleotide polymorphisms (SNPs) located within previously identified linkage peaks for schizophrenia reported associations between positive symptoms and a SNP within $O R C 3 L$ and disorganized symptoms with variation in BAI3 $(\mathrm{N}=178)$ [21].

The GWAS-derived risk allele in ZNF804A was associated with increased psychotic positive symptoms in 335 cases [22], while carriers of the MIR-137 risk allele demonstrated lower levels of positive symptoms in a sample of 821 patients [23]. A GWAS investigating the genetic relationship to three symptom dimensions (positive, negative/disorganized, and mood) revealed no associations with specific loci in 2,454 patients, but increased polygenic risk scores derived from a case-control GWAS of schizophrenia were significantly correlated with the negative/disorganized dimension in these 2,454 cases, indicating a stronger relationship between schizophrenia risk and these symptoms than for other symptom dimensions [24•]. Another GWAS specifically investigating levels of negative symptoms identified no genome-wide significant associations, despite using 1,774 cases [25].

While no definitive associations with symptoms have emerged thus far, reported associations with negative symptoms slightly predominate. This may be a reflection of their relative ease of quantification, as they are more likely to emerge as a single factor in factor analysis and be more persistently enduring than the vacillating, treatmentamenable positive symptoms. They are also more readily observed by raters, as positive symptoms can only be determined by patient report [6]. 


\section{Family History}

The role of family history in genetic studies of schizophrenia has been a polarizing topic. On one hand, having a family member with schizophrenia is still among the most salient factors for risk prediction, and some evidence (reviewed below) suggests differences in rates of some genetic risk factors based on family history. However, for highly polygenic diseases such as schizophrenia, most families with a 'sporadic' affected individual actually have circulating risk variants [26], rendering the familial/sporadic distinction relatively meaningless from a genetic standpoint.

Genetic investigations incorporating family history information have yielded conflicting results. One early study of de novo mutations (i.e. not observed in the parents of the affected individual) in a sample of 53 sporadic cases, 22 controls, and their parents found an excess of these changes in the cases and posited that, in conjunction with $\mathrm{CNV}$ estimates, de novo variants were responsible for $>50 \%$ of sporadic cases [27]. The same research group later revised these estimates downward following analysis of a sample of 231 patient-parent trios, alleging that one-quarter to one-third of sporadic schizophrenia cases are due to de novo events [28]. However, a larger, more recent exome-sequencing study of 617 probands and their parents observed no differences in mutation rates between cases with and without a family history of schizophrenia [29].

Another recent study in 386 Irish cases found that carriers of rare CNV deletions or combined deletions/duplications that intersected brain-expressed genes were less likely to have a family history of schizophrenia, although without parental genotypes, it was not possible to determine whether these were inherited [30]. Common genetic variation has also been assessed in a GWAS conducted separately for cases with $(\mathrm{N}=$ 527) and without $(\mathrm{N}=1,661)$ a family history of schizophrenia compared with control subjects $(\mathrm{N}=3,187)$, but no significant associations were revealed following correction for multiple tests [31•]. Amid these conflicting reports, consensus has yet to emerge regarding the relationship between genetic markers and family history of schizophrenia.

\section{Age at Onset}

Since early age at onset (AAO) curtails education and integration into society and is related to poor prognosis [32], understanding the biological (and environmental) influences modulating onset timing is a worthwhile goal. The two published GWAS of AAO in schizophrenia $(\mathrm{N}=1,162$ and 2,387) $[31 \bullet, 33]$ and another linkage study in 170 related pairs of subjects [34] all failed to identify genetic loci significantly impacting this measure. However, several associations between AAO and schizophrenia candidate genes have been reported. A protective haplotype of $N R G 1$ demonstrated association with earlier onset using a quantitative measure in 1,071 subjects [19]. A study of DTNBP1 in 268 families reported some haplotypes segregating with early-onset schizophrenia and others with adult onset [35]. Variants within the estrogen receptor alpha gene were associated with earlier $\mathrm{AAO}$, and post hoc tests revealed this was driven by the female subjects (total $\mathrm{N}=303 ; 151$ females) [36]. The $B D N F$ $\mathrm{val} /$ met polymorphism was associated with earlier AAO in male $(\mathrm{N}=117)$ but not female $(\mathrm{N}=91)$ paranoid schizophrenics [37].

Childhood-onset schizophrenia (COS) has received special attention as an early-onset subgroup within the schizophrenia patient population. While many studies have concentrated on clinical and neuroanatomical differences, some have investigated possible genetic differences in COS. Rare CNVs associated with schizophrenia are often de novo events and are enriched in cases with early/childhood onset (adult-onset cases $=74$, early onset $=76, \operatorname{COS}=83$ ) [38]. Carriers of de novo single nucleotide changes do not appear to have earlier AAO as a whole [29], although this has not yet been thoroughly investigated in COS.

\section{Severity/Course of Illness}

As with AAO, illness severity can be investigated as either a quantitative or a binary trait, and one of the main challenges of studying this trait is defining it. Symptom levels, number of hospitalizations, treatment resistance, and the patterns of psychotic episodes over time could all be indices of illness severity but may have very different underlying causes.

A GWAS of patients with mild $(\mathrm{N}=496)$ versus severe $(\mathrm{N}=$ $1,436)$ course of illness yielded no significant associations [31•]. Another GWAS tested for associations with severity by treatment group in the Clinical Antipsychotic Trial of Intervention Effectiveness (CATIE) sample consisting of 738 patients [39]. Three SNPs in PDE4D mediated effects of quetiapine on severity. Genetic variants in TJP1 and PPA2 were related to severity while receiving risperidone as reported by patients and clinicians, respectively. The robustly associated risk allele in the ZNF804A gene also appears to confer risk for increased positive symptom severity in a sample of 335 patients [22], and SNPs in the membrane-bound isoform of $C O M T$ were associated with negative symptom severity in 238 patients [8].

\section{Sex}

The epidemiological observation that more males than females receive schizophrenia diagnoses [40], in combination with other differences by sex, such as earlier onset and more 
severe course in men $[41,42]$, has prompted genetic investigations of sex-specific effects (present in only one sex) and sex-dependent effects (exerting differential influences by sex). Almost all studies of schizophrenia risk by sex have examined specific genes; however, one GWAS for schizophrenia risk in males (1,850 cases, 1,441 controls) and females (912 cases, 1,746 controls) separately was conducted and yielded no significant results [31•]. A comprehensive review of the literature on schizophrenia candidate genes and sex was recently published by Goldstein et al. [43•], who found that associations have either been isolated reports or been inconsistently significant when examined in multiple studies. Interestingly, the authors noted that most of the sex-specific reports have been in females. A possible explanation for this is that malespecific effects could be predominantly localized to the sex chromosomes, since their haploid status leads to expression of any genetic problems, while females enjoy the buffering effects of a second $\mathrm{X}$ chromosome and, of course, no Y. Unfortunately, the $\mathrm{X}$ chromosome is frequently excluded from analyses due to the difficulties presented by haploid males and diploid females, and Y chromosome markers are included even less often.

An alternative possibility is that the genetic risk factors do not differ between sexes, but that being male inherently increases risk for schizophrenia. This concept is illustrated by studies of height, which show similar effects of statureassociated genetic loci for both men and women, but shifted distributions by sex [44].

\section{Cognitive Impairments}

Cognitive deficits are widely acknowledged as a core feature of schizophrenia; however, the extent of impairment varies substantially across individuals, and relatively little is known about its genetic basis. Some candidate genes such as RELN $(\mathrm{N}=938)$ [20], MAGI2 $(\mathrm{N}=114)$ [45], DBH $(\mathrm{N}=195)$ [46], and $B D N F(\mathrm{~N}=657)$ [47] have been associated with measures of cognition with varying levels of confidence. However, many other recent studies have concentrated on cognitionmodifying properties of GWAS-identified loci. The CSMD1 risk allele was associated with worse overall cognitive ability and memory function, but not attention, in samples from Ireland (387 cases, 171 controls) and Germany (205 cases, 533 controls) [48]. A GWAS-identified risk allele in the major histocompatibility complex was associated with both episodic memory and hippocampal volume in patients with schizophrenia $(\mathrm{N}=346)$ and healthy comparison subjects $(\mathrm{N}=$ 2,382) [49]. Reduced attentional control in ZNF804A risk allele homozygotes was observed in a sample of 63 healthy adults [50], but attention and working memory in a sample of 1,507 healthy males was not significantly affected by riskallele carrier status [51]. In one study of 596 patients with psychosis spectrum disorders, carriers of the TCF4 risk allele demonstrated poorer verbal fluency and learning [52], but another study reported better cognitive function in patients $(\mathrm{N}=580)$ and worse in controls $(\mathrm{N}=498)$ with the risk allele [53]. Using a novel approach, one study of 617 patients empirically defined two groups based on cognitive symptoms, and the MIR-137 risk allele in combination with increased negative symptoms predicted membership in the cognitive deficit subgroup [54]. Cognitive deficits involving episodic memory and attentional control were also observed in MIR137 risk allele carriers with schizophrenia $(\mathrm{N}=329)$, schizoaffective disorder $(\mathrm{N}=70)$, or no diagnosis $(\mathrm{N}=171)$ in a separate study [23].

Aggregated genetic risk for schizophrenia was associated with a relative cognitive decline between 11 and 70 years of age in 937 healthy subjects, indicating some common genetic factors [55]. A GWAS explicitly examining cognitive decline in schizophrenia revealed no significant loci, but had limited power, with only 166 subjects [56]. Additional studies are needed to confirm the tentative findings so far, and the relationship between genetic influences on cognition overall and specifically in the context of schizophrenia also merits further attention.

\section{Gene x Environment Subgroups}

In genetically susceptible individuals, some environmental exposures could lead to the development of schizophrenia, and these paths to this diagnosis may constitute etiologically distinct subgroups. Cannabis use is a particularly strong candidate for gene $\mathrm{x}$ environment interaction precipitating a schizophrenia diagnosis, and markers within COMT [57, 58] and $A K T 1$ [59] have been specifically tied to this interaction in large samples $(\mathrm{N}>700)$. Exposures to some pathogens, including Toxoplasma gondii and human herpesvirus-2 during sensitive developmental periods have also been implicated through multiple lines of evidence [60], and toxoplasmosisrelated schizophrenia has been specifically investigated as a subtype in 194 toxoplasma-free and 57 infected patients. The infected patients scored higher on positive symptoms, and several measures of psychopathology were associated with lower titers of anti-toxoplasma antibodies, suggesting that greater duration of infection is related to deteriorating course of illness [61].

Epidemiological evidence suggests that low birth weight may differentially impact children at high genetic risk for schizophrenia [62], although the relationship between obstetric complications and genes is far from clear [63]. Other environmental measures that have been tied to schizophrenia, such as living in an urban environment [64], may monotonically increase risk or interact with genetic risk factors. 


\section{Other Phenotypes}

In addition to the aforementioned types of variation, a number of other less-often researched domains exist. Although the Diagnostic and Statistical Manual of Mental Disorders (DSM)-5 has not retained them, five clinical subtypes were put forth in the DSM-IV-TR [65]: disorganized, paranoid, undifferentiated, residual, and catatonic [66]. For the most part, these categories were not conducive to research and were rarely used. Paranoid schizophrenia has been the only DSM subtype to receive much attention in a research capacity. The aforementioned study linking $B D N F$ and AAO [37] was conducted in a population of paranoid schizophrenia patients, and other recent genetic studies in this subgroup have reported associations with variation in the DRD5 (176 patients, 206 controls) [67] and HTR1A (161 patients, 182 controls) [68] genes. None of these studies tested for associations in non-paranoid schizophrenia subjects, impeding interpretation of whether these are truly subgroup-specific associations.

Deficit schizophrenia refers to a presentation with primary and enduring negative symptoms; this was proposed as a potential subtype in 1988 [69] and implemented as such in a recent genetic association study of five candidate genes treating deficit $(\mathrm{N}=153)$ and non-deficit $(\mathrm{N}=127)$ cases as distinct subgroups and comparing them with healthy controls $(\mathrm{N}=230)$. Nominal associations with SNPs in NRG1 and $D T N B P 1$ were detected for schizophrenia risk in the nondeficit group [70], supporting prior associations of DTNBP1 as a modifier of negative symptoms [6].

Advanced paternal age has been linked to risk for schizophrenia [71], and k-means clustering of patients with $(\mathrm{N}=34)$ and without $(\mathrm{N}=136)$ older fathers based on demographic, symptom, and cognitive measures yielded some clusters with high proportions of cases with older fathers [72], suggesting they may define a subtype notable for having relatively higher verbal compared with performance intelligence.

Treatment response almost certainly has some genetic basis, conferring modifying properties. However, certain drugs may improve symptoms in some patients because they have a common underlying pathophysiology (i.e. a subgroup). Pharmacogenomic investigations in schizophrenia have so far not yielded promising results in terms of modifier locus identification or defining subgroups [73]. A GWAS of response to five common antipsychotics (olanzapine, quetiapine, risperidone, ziprasidone, and perphenazine) in 738 subjects yielded no variants with strong associations [74]. Some individual genes have also been investigated as potential modifiers of antipsychotic response, including one report of attenuated amelioration of positive symptoms in response to antipsychotic medications for carriers of the risk allele within $Z N F 804 A$ in a sample of 144 patients [75]. Variation within the cytochrome p450 gene, CYP2D6, involved in the metabolism of many drugs, has been extensively studied, but a recent review and meta-analysis determined there is little evidence to support its role in the efficacy of antipsychotic medications [76].

\section{Discussion}

As we begin to understand the genetic risk for the construct termed 'schizophrenia', the next major task is to disentangle the complex relationships between genetic and clinical heterogeneity. Many studies have attempted to connect genetic risk factors to AAO, family history, severity, sex, symptoms, environmental exposures, and other clinical features, but few attempts at replication have been made for most of the resultant findings. Furthermore, the same problems of limited genomic coverage and small samples that have historically plagued genetic association studies of risk for schizophrenia continue to thwart the majority of these investigations. Conclusive genetic subtype and modifier associations in schizophrenia have yet to emerge.

As alluded to throughout this review, complex relationships exist between many of the variable characteristics of schizophrenia. Early AAO and increased illness severity have been strongly and consistently correlated $[31 \bullet, 32]$. On average, males also have an earlier onset than females, and, unsurprisingly, a worse prognosis $[41,77]$. Such interactions add to the difficulty in studying heterogeneity in schizophrenia and may be potential confounders.

One of the main difficulties with studies of phenotypic heterogeneity is the unstandardized nature of many of the measurements. Even apparently straightforward metrics such as AAO can refer to age at first symptoms, diagnosis, or hospitalization, and may be subject to recall bias or local healthcare availability. Symptoms vary over time and hinge on accurate reporting in a population that may be reluctant to fully disclose this information. Other measures such as severity and cognitive deficits are also open to interpretation and variably defined.

Subjective categorizations may slowly give way to objective measures as the genetic risk for schizophrenia is identified with increasing confidence. The low effect sizes of the associated variants emerging from GWAS may partially result from dilution due to etiological heterogeneity within the case groups. However, the identified variants offer new opportunities to group patients by the constellations of risk markers they harbor. Clustering patients in this manner has been advocated in terms of autism research [78] and is becoming tractable for schizophrenia investigations as well. These objective genotypes offer a more solid foundation on which to identify subtypes from an etiological standpoint, and characterizing clinical differences and potential modifying loci would 
logically follow from identification of biologically defined subgroups.

Most investigations of modifying loci have understandably centered on the more research-amenable set of identified risk variants for schizophrenia. Studies of inconsistently associated candidate genes are waning as the more statistically sound GWAS-identified genes step in to replace them. Increasingly, genome-wide searches have also been implemented in studies of subtypes and modifiers. Studies of rare and de novo CNVs and mutations are also growing in number as the methods to detect them improve in quality and decrease in cost.

In addition to the technological advances in genotyping, methodological developments have been made to aid in this endeavor. Since it may be difficult to know a priori whether subtype or modifier paradigms best fit a genotype-phenotype relationship, statistical methods to simultaneously investigate modifier and subtype associations were created [79•]. Dimensional approaches, exploring symptoms regardless of diagnoses, are currently en vogue and compatible with studies of this kind but have not yet been widely implemented.

Many of the CNVs and some of the SNPs associated with schizophrenia also confer risk for other psychiatric disorders $[80,81]$, and many symptoms are also shared with a range of psychiatric problems. These pleiotropic effects and crossdisorder phenotypes are beyond the scope of this review, but bear further scrutiny. The biological mechanisms by which these genes exert their effects on clinically relevant behavior remain obscure and mandate additional research. Biomarkers, intermediate between the genes and behavior, have been elusive in psychiatry, but are often heralded as a way to revolutionize diagnostic procedures and would almost certainly also prove useful in efforts to define more similar groups of patients.

Observable variations in schizophrenia may partially stem from population differences. Most genetic studies of schizophrenia have involved subjects of European or East Asian ancestry, with very little contribution from other populations. A comprehensive understanding of the influences leading to schizophrenia in its many manifestations will necessitate global participation. As a step in this direction, investigations of genetic modifiers of symptoms, AAO, risk differences by sex, and other genetic modifiers and subtypes are currently underway using subjects from the 49 non-overlapping samples comprising the Psychiatric Genomics Consortium, which have already yielded unprecedented evidence for novel susceptibility genes [82]. Just as more definitive findings have emerged from large collaborative GWAS, consortia addressing variations in schizophrenia will be able to offer more authoritative conclusions.

Acknowledgments The helpful comments and advice from Ayman $\mathrm{H}$. Fanous, M.D. during the generation of this manuscript are gratefully acknowledged. Additionally, this work was supported by a National
Alliance for Research on Schizophrenia and Depression (NARSAD) Young Investigator grant to SEB.

\section{Compliance with Ethics Guidelines}

Conflict of Interest Sarah Bergen has no potential conflicts of interest relevant to this article to report.

Human and Animal Rights and Informed Consent This article does not contain any studies with human or animal subjects performed by any of the authors.

\section{References}

Papers of particular interest, published recently, have been highlighted as:

- of importance

1. Bleuler E. Dementia Praecox oder Gruppe Der Schizophrenien. Leipzig: F. Deuticke; 1911.

2. Kraeplin E. Psychiatrie. Leipzig: J. A. Barth; 1909.

3. Bergen SE, Maher BS, Fanous AH, Kendler KS. Detection of susceptibility genes as modifiers due to subgroup differences in complex disease. Eur J Hum Genet. 2010;18(8):960-4. doi:10. 1038/ejhg.2010.39.

4. Fanous AH, Kendler KS. Genetic heterogeneity, modifier genes, and quantitative phenotypes in psychiatric illness: searching for a framework. Mol Psychiatry. 2005;10(1):6-13. doi:10.1038/sj.mp. 4001571.

5. Cohen RZ, Seeman MV, Gotowiec A, Kopala L. Earlier puberty as a predictor of later onset of schizophrenia in women. Am J Psychiatry. 1999;156(7):1059-64.

6. Fanous AH, Kendler KS. Genetics of clinical features and subtypes of schizophrenia: a review of the recent literature. Curr Psychiatry Rep. 2008;10(2):164-70.

7. Wang Y, Fang Y, Shen Y, Xu Q. Analysis of association between the catechol-O-methyltransferase (COMT) gene and negative symptoms in chronic schizophrenia. Psychiatry Res. 2010;179(2): 147-50. doi:10.1016/j.psychres.2009.03.029.

8. Wright GE, Niehaus DJ, van der Merwe L, Koen L, Korkie LJ, Kinnear CJ, et al. Association of MB-COMT polymorphisms with schizophrenia: susceptibility and symptom severity in an African cohort. Prog Neuro-Psychopharmacol Biol Psychiatry. 2012;39(1): 163-9. doi:10.1016/j.pnpbp.2012.06.006.

9. Kang WS, Park JK, Park HJ, Kim SK, Cho AR, Lee SM, et al. Association between catechol-O-methyltransferase Val158Met polymorphism and negative symptoms of schizophrenia in the Korean population. Psychiatry Res. 2012;198(2):338-9. doi:10. 1016/j.psychres.2011.12.048.

10. Chen CY, Lu RB, Yeh YW, Shih MC, Huang SY. Association study of catechol-O-methyltransferase gene polymorphisms with schizophrenia and psychopathological symptoms in Han Chinese. Genes Brain Behav. 2011;10(3):316-24. doi:10.1111/j.1601-183X.2010. 00670.x.

11. Tovilla-Zarate C, Medellin BC, Fresan A, Lopez-Narvaez L, Castro TB, Juarez Rojop I, et al. No association between catechol-omethyltransferase Val108/158Met polymorphism and schizophrenia or its clinical symptomatology in a Mexican population. Mol Biol Rep. 2013;40(2):2053-8. doi:10.1007/s11033-012-2264-x. 
12. Zhou N, Yu Q, Li X, Yu Y, Kou C, Li W, et al. Association of the dopamine beta-hydroxylase $19 \mathrm{bp}$ insertion/deletion polymorphism with positive symptoms but not tardive dyskinesia in schizophrenia. Hum Psychopharmacol. 2013;28(3):230-7. doi:10.1002/hup.2311.

13. Chien YL, Hwu HG, Fann CS, Chang CC, Tsuang MT, Liu CM. DRD2 haplotype associated with negative symptoms and sustained attention deficits in Han Chinese with schizophrenia in Taiwan. J Hum Genet. 2013;58(4):229-32. doi:10.1038/jhg. 2012.157.

14. Sun MM, Yang LM, Wang Y, Feng X, Cui KY, Liu LF, et al. BDNF Val66Met polymorphism and anxiety/depression symptoms in schizophrenia in a Chinese Han population. Psychiatr Genet. 2013;23(3):124-9. doi:10.1097/YPG.0b013e328360c866.

15. Li W, Zhou N, Yu Q, Li X, Yu Y, Sun S, et al. Association of BDNF gene polymorphisms with schizophrenia and clinical symptoms in a Chinese population. Am J Med Genet B Neuropsychiatr Genet. 2013;162B(6):538-45. doi:10.1002/ajmg.b.32183.

16. Liu H, Wang C, Chen PH, Zhang BS, Zheng YL, Zhang CX, et al. Association of the manganese superoxide dismutase gene Ala-9Val polymorphism with clinical phenotypes and tardive dyskinesia in schizophrenic patients. Prog Neuro-Psychopharmacol Biol Psychiatry. 2010;34(4):692-6. doi:10.1016/j.pnpbp.2010.03.026.

17. Souza RP, Tampakeras M, Basile V, Shinkai T, Rosa DV, Potkin S, et al. Lack of association of GPX1 and MnSOD genes with symptom severity and response to clozapine treatment in schizophrenia subjects. Hum Psychopharmacol. 2009;24(8):676-9. doi:10.1002/ hup.1076.

18. Park HJ, Kim JW, Lee SK, Kim SK, Park JK, Cho AR, et al. Association between the SLC6A12 gene and negative symptoms of schizophrenia in a Korean population. Psychiatry Res. 2011;189(3):478-9. doi:10.1016/j.psychres.2011.01.023.

19. Papiol S, Begemann M, Rosenberger A, Friedrichs H, Ribbe K, Grube S, et al. A phenotype-based genetic association study reveals the contribution of neuregulin1 gene variants to age of onset and positive symptom severity in schizophrenia. Am J Med Genet B Neuropsychiatr Genet. 2011;156B(3):340-5. doi:10.1002/ajmg.b. 31168.

20. Wedenoja J, Tuulio-Henriksson A, Suvisaari J, Loukola A, Paunio $\mathrm{T}$, Partonen T, et al. Replication of association between working memory and Reelin, a potential modifier gene in schizophrenia. Biol Psychiatry. 2010;67(10):983-91. doi:10.1016/j.biopsych. 2009.09.026.

21. DeRosse P, Lencz T, Burdick KE, Siris SG, Kane JM, Malhotra AK. The genetics of symptom-based phenotypes: toward a molecular classification of schizophrenia. Schizophr Bull. 2008;34(6): 1047-53. doi:10.1093/schbul/sbn076.

22. Wassink TH, Epping EA, Rudd D, Axelsen M, Ziebell S, Fleming $\mathrm{FW}$, et al. Influence of ZNF804a on brain structure volumes and symptom severity in individuals with schizophrenia. Arch Gen Psychiatry. 2012;69(9):885-92. doi:10.1001/archgenpsychiatry. 2011.2116.

23. Cummings E, Donohoe G, Hargreaves A, Moore S, Fahey C, Dinan TG, et al. Mood congruent psychotic symptoms and specific cognitive deficits in carriers of the novel schizophrenia risk variant at MIR-137. Neurosci Lett. 2013;532:33-8. doi:10.1016/j.neulet. 2012.08.065.

24. Fanous AH, Zhou B, Aggen SH, Bergen SE, Amdur RL, Duan J, et al. Genome-wide association study of clinical dimensions of schizophrenia: polygenic effect on disorganized symptoms. Am J Psychiatry. 2012;169(12):1309-17. doi:10.1176/appi.ajp.2012. 12020218. This is the first GWAS of symptom dimensions in schizophrenia in a large sample and offers evidence that negativel disorganized symptoms are most closely related to genetic risk for schizophrenia.

25. Xu C, Aragam N, Li X, Villla EC, Wang L, Briones D, et al. BCL9 and $\mathrm{C} 9$ orf5 are associated with negative symptoms in schizophrenia: meta-analysis of two genome-wide association studies. PLoS One. 2013;8(1):e51674. doi:10.1371/journal.pone. 0051674.

26. Yang J, Visscher PM, Wray NR. Sporadic cases are the norm for complex disease. Eur J Hum Genet. 2010;18(9):1039-43. doi:10. 1038/ejhg.2009.177.

27. Xu B, Roos JL, Dexheimer P, Boone B, Plummer B, Levy S, et al Exome sequencing supports a de novo mutational paradigm for schizophrenia. Nat Genet. 2011;43(9):864-8. doi:10.1038/ng.902.

28. Xu B, Ionita-Laza I, Roos JL, Boone B, Woodrick S, Sun Y, et al De novo gene mutations highlight patterns of genetic and neural complexity in schizophrenia. Nat Genet. 2012;44(12):1365-9. doi: 10.1038/ng.2446.

29. Fromer M, Pocklington AJ, Kavanagh DH, Williams HJ, Dwyer S, Gormley P, et al. De novo mutations in schizophrenia implicate synaptic networks. Nature. 2014;506(7487):179-84. doi:10.1038/ nature12929.

30. Merikangas AK, Segurado R, Cormican P, Heron EA, Anney RJ, Moore $\mathrm{S}$, et al. The phenotypic manifestations of rare CNVs in schizophrenia. Schizophr Res. 2014. doi:10.1016/j.schres.2014.06. 016.

31. Bergen SE, O'Dushlaine CT, Lee PH, Fanous AH, Ruderfer DM, Ripke S, et al. Genetic modifiers and subtypes in schizophrenia: investigations of age at onset, severity, sex and family history. Schizophr Res. 2014;154(1-3):48-53. doi:10.1016/j.schres.2014. 01.030. A recent study exploring several main modifying and subtyping variables in a modern GWAS framework - most for the first time with this method.

32. Rabinowitz J, Levine SZ, Hafner H. A population based elaboration of the role of age of onset on the course of schizophrenia. Schizophr Res. 2006;88(1-3):96-101. doi:10.1016/j. schres.2006.07.007.

33. Wang KS, Liu X, Zhang Q, Aragam N, Pan Y. Genome-wide association analysis of age at onset in schizophrenia in a European-American sample. Am J Med Genet B Neuropsychiatr Genet. 2011;156B(6):671-80. doi:10.1002/ajmg.b.31209.

34. Hamshere ML, Holmans PA, McCarthy GM, Jones LA, Murphy $\mathrm{KC}$, Sanders RD, et al. Phenotype evaluation and genomewide linkage study of clinical variables in schizophrenia. Am J Med Genet B Neuropsychiatr Genet. 2011;156B(8):929-40. doi:10. 1002/ajmg.b.31240

35. Fatjo-Vilas M, Papiol S, Estrada G, Bombin I, Peralta V, Rosa A, et al. Dysbindin-1 gene contributes differentially to early- and adultonset forms of functional psychosis. Am J Med Genet B Neuropsychiatr Genet. 2011;156B(3):322-33. doi:10.1002/ajmg. b.31166.

36. Wang S, Li W, Zhao J, Zhang H, Yang Y, Wang X, et al. Association of estrogen receptor alpha gene polymorphism with age at onset, general psychopathology symptoms, and therapeutic effect of schizophrenia. Behav Brain Funct. 2013;9:12. doi:10. 1186/1744-9081-9-12.

37. Suchanek R, Owczarek A, Paul-Samojedny M, Kowalczyk M, Kucia K, Kowalski J. BDNF val66met polymorphism is associated with age at onset and intensity of symptoms of paranoid schizophrenia in a Polish population. J Neuropsychiatry Clin Neurosci. 2013;25(1):88-94. doi:10.1176/appi.neuropsych. 11100234.

38. Walsh T, McClellan JM, McCarthy SE, Addington AM, Pierce SB, Cooper GM, et al. Rare structural variants disrupt multiple genes in neurodevelopmental pathways in schizophrenia. Science. 2008;320(5875):539-43. doi:10.1126/science.1155174.

39. Clark SL, Souza RP, Adkins DE, Aberg K, Bukszar J, McClay JL, et al. Genome-wide association study of patient-rated and clinicianrated global impression of severity during antipsychotic treatment. Pharmacogenet Genomics. 2013;23(2):69-77. doi:10.1097/FPC. 0b013e32835ca260. 
40. Saha S, Chant D, Welham J, McGrath J. A systematic review of the prevalence of schizophrenia. PLoS Med. 2005;2(5):e141. doi:10. 1371/journal.pmed.0020141.

41. Angermeyer MC, Kuhn L. Gender differences in age at onset of schizophrenia. An overview. Eur Arch Psychiatry Neurol Sci. 1988;237(6):351-64.

42. Lang FU, Kosters $M$, Lang S, Becker T, Jager M. Psychopathological long-term outcome of schizophrenia - a review. Acta Psychiatr Scand. 2013;127(3):173-82. doi:10.1111/ acps. 12030.

43. Goldstein JM, Cherkerzian S, Tsuang MT, Petryshen TL. Sex differences in the genetic risk for schizophrenia: history of the evidence for sex-specific and sex-dependent effects. Am J Med Genet B Neuropsychiatr Genet. 2013;162B(7):698-710. doi:10. 1002/ajmg.b.32159. An excellent review of sex differences in schizophrenia and studies exploring the genetic basis for the observed differences.

44. Randall JC, Winkler TW, Kutalik Z, Berndt SI, Jackson AU, Monda KL, et al. Sex-stratified genome-wide association studies including 270,000 individuals show sexual dimorphism in genetic loci for anthropometric traits. PLoS Genet. 2013;9(6):e1003500. doi:10.1371/journal.pgen.1003500.

45. Koide T, Banno M, Aleksic B, Yamashita S, Kikuchi T, Kohmura $\mathrm{K}$, et al. Common variants in MAGI2 gene are associated with increased risk for cognitive impairment in schizophrenic patients. PLoS One. 2012;7(5):e36836. doi:10.1371/journal.pone.0036836.

46. Hui L, Zhang X, Yu YQ, Han M, Huang XF, da Chen C, et al. Association between DBH 19 bp insertion/deletion polymorphism and cognition in first-episode schizophrenic patients. Schizophr Res. 2013;147(2-3):236-40. doi:10.1016/j.schres. 2013.04.035.

47. Zhang XY, da Chen C, Xiu MH, Haile CN, Luo X, Xu K, et al. Cognitive and serum BDNF correlates of BDNF Val66Met gene polymorphism in patients with schizophrenia and normal controls. Hum Genet. 2012;131(7):1187-95. doi: 10.1007/s00439-012-1150-x.

48. Donohoe G, Walters J, Hargreaves A, Rose EJ, Morris DW, Fahey C, et al. Neuropsychological effects of the CSMD1 genome-wide associated schizophrenia risk variant rs10503253. Genes Brain Behav. 2013;12(2):203-9. doi:10.1111/gbb.12016.

49. Walters JT, Rujescu D, Franke B, Giegling I, Vasquez AA, Hargreaves A, et al. The role of the major histocompatibility complex region in cognition and brain structure: a schizophrenia GWAS follow-up. Am J Psychiatry. 2013;170(8):877-85. doi:10. 1176/appi.ajp.2013.12020226.

50. Voineskos AN, Lerch JP, Felsky D, Tiwari A, Rajji TK, Miranda D, et al. The ZNF804A gene: characterization of a novel neural risk mechanism for the major psychoses. Neuropsychopharmacology. 2011;36(9):1871-8. doi:10.1038/npp.2011.72.

51. Stefanis NC, Hatzimanolis A, Smyrnis N, Avramopoulos D, Evdokimidis I, van Os J, et al. Schizophrenia candidate gene ERBB4: covert routes of vulnerability to psychosis detected at the population level. Schizophr Bull. 2013;39(2):349-57. doi:10.1093/ schbul/sbr169.

52. Wirgenes KV, Sonderby IE, Haukvik UK, Mattingsdal M, Tesli M, Athanasiu L, et al. TCF4 sequence variants and mRNA levels are associated with neurodevelopmental characteristics in psychotic disorders. Transl Psychiatry. 2012;2:e112. doi:10.1038/tp.2012.39.

53. Zhu X, Gu H, Liu Z, Xu Z, Chen X, Sun X, et al. Associations between TCF4 gene polymorphism and cognitive functions in schizophrenia patients and healthy controls. Neuropsychopharmacology. 2013;38(4):683-9. doi:10.1038/npp. 2012.234.

54. Green MJ, Cairns MJ, Wu J, Dragovic M, Jablensky A, Tooney PA, et al. Genome-wide supported variant MIR137 and severe negative symptoms predict membership of an impaired cognitive subtype of schizophrenia. Mol Psychiatry. 2013;18(7):774-80. doi:10.1038/ mp.2012.84.

55. McIntosh AM, Gow A, Luciano M, Davies G, Liewald DC, Harris SE, et al. Polygenic risk for schizophrenia is associated with cognitive change between childhood and old age. Biol Psychiatry. 2013;73(10):938-43. doi:10.1016/j.biopsych.2013.01.011.

56. Hashimoto R, Ikeda M, Ohi K, Yasuda Y, Yamamori H, Fukumoto $\mathrm{M}$, et al. Genome-wide association study of cognitive decline in schizophrenia. Am J Psychiatry. 2013;170(6):683-4. doi:10.1176/ appi.ajp.2013.12091228.

57. Costas J, Sanjuan J, Ramos-Rios R, Paz E, Agra S, Tolosa A, et al. Interaction between COMT haplotypes and cannabis in schizophrenia: a case-only study in two samples from Spain. Schizophr Res. 2011;127(1-3):22-7. doi:10.1016/j.schres.2011.01.014.

58. Caspi A, Moffitt TE, Cannon M, McClay J, Murray R, Harrington $\mathrm{H}$, et al. Moderation of the effect of adolescent-onset cannabis use on adult psychosis by a functional polymorphism in the catechol-Omethyltransferase gene: longitudinal evidence of a gene $\mathrm{X}$ environment interaction. Biol Psychiatry. 2005;57(10):1117-27. doi:10. 1016/j.biopsych.2005.01.026.

59. van Winkel R, Genetic R. Outcome of Psychosis I. Family-based analysis of genetic variation underlying psychosis-inducing effects of cannabis: sibling analysis and proband follow-up. Arch Gen Psychiatry. 2011;68(2):148-57. doi:10.1001/archgenpsychiatry. 2010.152.

60. Arias I, Sorlozano A, Villegas E, de Dios LJ, McKenney K, Cervilla $\mathrm{J}$, et al. Infectious agents associated with schizophrenia: a metaanalysis. Schizophr Res. 2012;136(1-3):128-36. doi:10.1016/j. schres.2011.10.026.

61. Holub D, Flegr J, Dragomirecka E, Rodriguez M, Preiss M, Novak $\mathrm{T}$, et al. Differences in onset of disease and severity of psychopathology between toxoplasmosis-related and toxoplasmosisunrelated schizophrenia. Acta Psychiatr Scand. 2013;127(3):22738. doi:10.1111/acps.12031.

62. Forsyth JK, Ellman LM, Tanskanen A, Mustonen U, Huttunen MO, Suvisaari J, et al. Genetic risk for schizophrenia, obstetric complications, and adolescent school outcome: evidence for geneenvironment interaction. Schizophr Bull. 2013;39(5):1067-76. doi:10.1093/schbul/sbs098.

63. Mittal VA, Ellman LM, Cannon TD. Gene-environment interaction and covariation in schizophrenia: the role of obstetric complications. Schizophr Bull. 2008;34(6):1083-94. doi:10.1093/schbul/ sbn080.

64. Vassos E, Pedersen CB, Murray RM, Collier DA, Lewis CM. Meta-analysis of the association of urbanicity with schizophrenia. Schizophr Bull. 2012;38(6):1118-23. doi:10.1093/schbul/ sbs096.

65. Association AP. Diagnostic and Statistical Manual IV, Text Revision (DSM-IV-TR). Washington, DC: American Psychiatric Association; 2000.

66. McGlashan TH, Fenton WS. Classical subtypes for schizophrenia: literature review for DSM-IV. Schizophr Bull. 1991;17(4):609-32.

67. Zhao Y, Ding M, Pang H, Xu XM, Wang BJ. Relationship between genetic polymorphisms in the DRD5 gene and paranoid schizophrenia in northern Han Chinese. Genet Mol Res. 2014;13(1): 1609-18. doi:10.4238/2014.March.12.13.

68. Zhou X, Ding M, Ding C, Yao J, Pang H, Xing J, et al. Relationship between genetic polymorphisms in the HTR1A gene and paranoid schizophrenia in a northern Han Chinese population. J Mol Neurosci. 2013;49(3):625-31. doi:10.1007/s12031-012-9928-9.

69. Carpenter Jr WT, Heinrichs DW, Wagman AM. Deficit and nondeficit forms of schizophrenia: the concept. Am J Psychiatry. 1988;145(5):578-83.

70. Rethelyi JM, Bakker SC, Polgar P, Czobor P, Strengman E, Pasztor PI, et al. Association study of NRG1, DTNBP1, RGS4, G72/G30, and PIP5K2A with schizophrenia and symptom severity in a 
Hungarian sample. Am J Med Genet B Neuropsychiatr Genet. 2010;153B(3):792-801. doi:10.1002/ajmg.b.31049.

71. Frans EM, McGrath JJ, Sandin S, Lichtenstein P, Reichenberg A, Langstrom N, et al. Advanced paternal and grandpaternal age and schizophrenia: a three-generation perspective. Schizophr Res. 2011;133(1-3):120-4. doi:10.1016/j.schres.2011.09.027.

72. Lee H, Malaspina D, Ahn H, Perrin M, Opler MG, Kleinhaus K, et al. Paternal age related schizophrenia (PARS): latent subgroups detected by k-means clustering analysis. Schizophr Res. 2011;128(1-3):143-9. doi:10.1016/j.schres.2011.02.006.

73. Kohlrausch FB. Pharmacogenetics in schizophrenia: a review of clozapine studies. Rev Bras Psiquiatr. 2013;35(3):305-17. doi:10. 1590/1516-4446-2012-0970.

74. McClay JL, Adkins DE, Aberg K, Bukszar J, Khachane AN, Keefe RS, et al. Genome-wide pharmacogenomic study of neurocognition as an indicator of antipsychotic treatment response in schizophrenia. Neuropsychopharmacology. 2011;36(3):616-26. doi:10.1038/ npp.2010.193.

75. Mossner R, Schuhmacher A, Wagner M, Lennertz L, Steinbrecher A, Quednow BB, et al. The schizophrenia risk gene ZNF804A influences the antipsychotic response of positive schizophrenia symptoms. Eur Arch Psychiatry Clin Neurosci. 2012;262(3):1937. doi:10.1007/s00406-011-0235-1.

76. Fleeman N, Dundar Y, Dickson R, Jorgensen A, Pushpakom S, McLeod C, et al. Cytochrome P450 testing for prescribing antipsychotics in adults with schizophrenia: systematic review and meta-analyses. Pharmacogenomics J. 2011;11(1):1-14. doi:10. 1038/tpj.2010.73.

77. Lewine RR. Sex differences in age of symptom onset and first hospitalization in schizophrenia. Am J Orthopsychiatry. 1980;50(2):316-22.

78. Stessman HA, Bernier R, Eichler EE. A genotype-first approach to defining the subtypes of a complex disease. Cell. 2014;156(5):8727. doi:10.1016/j.cell.2014.02.002.

79. Lee PH, Bergen SE, Perlis RH, Sullivan PF, Sklar P, Smoller JW, et al. Modifiers and subtype-specific analyses in whole-genome association studies: a likelihood framework. Hum Hered. 2011;72(1):10-20. doi:10.1159/000327158. This paper presents a methodological approach capable of simultaneously assessing both modifier and subtype genetic influences on a trait.

80. Malhotra D, Sebat J. CNVs: harbingers of a rare variant revolution in psychiatric genetics. Cell. 2012;148(6):1223-41. doi:10.1016/j. cell.2012.02.039.

81. Cross-Disorder Group of the Psychiatric Genomics C, Lee SH, Ripke S, Neale BM, Faraone SV, Purcell SM, et al. Genetic relationship between five psychiatric disorders estimated from genomewide SNPs. Nat Genet. 2013;45(9):984-94. doi:10.1038/ng.2711.

82. Schizophrenia Working Group of the Psychiatric Genomics C. Biological insights from 108 schizophrenia-associated genetic loci. Nature. 2014;511(7510):421-7. doi:10.1038/nature13595. 